\title{
Performance of Indian Cement Companies: A Super Efficiency DEA Study
}

\author{
Satish Chandrasekaran ${ }^{1}$ Asmita Chitnis ${ }^{2}$ \\ \{satish.kumar@siib.ac.in, asmitachitnis@gmail.com\} \\ Symbiosis Institute of International Business, Pune
}

\begin{abstract}
The cement industry of India is a major contibutor to its economy and generates huge employment opportunities. In the present study, the cement operating in India has been evaluated using Data Envelopment Analysis (DEA) and Super Efficiency Data Envelopment Analysis (SDEA) for measuring its operational efficiency, productivity and profitability. Data have been obtained on 17 Indian cement companies for the financial year 2017-18 on 4 input and 1 output variables which are Raw Material Cost, Power and Fuel Expenses, Salary \&Wages, Total Assets and Total Revenue respectively. Most of the big players like UltraTech, ACC Ltd. and Shree cement were both technical and scale efficient as expected but Super efficiency DEA analysis gave away surprising results. The less known and a small-scale company namely; OCL India Ltd. emerged as the most efficient cement producer followed by Prism Cement. It is evident from the study that the big players are not able to take the advantage of economies of scale.
\end{abstract}

Keywords: Performance, Benchmarking, Super Efficiency, DEA, Cement Industry

\section{Introduction}

In today's business environment, which is extremely dynamic, the greatest challenge is to remain competitive, and sustainable. Companies need to continuously invest in both consecutive and simultaneous projects to guarantee healthy and profitable growth. Business leaders are forced to improve their effectiveness and efficiency by comparing the performance of various projects on a continuous basis as the competition is getting intense with blurring boundaries across nations. With globalized economy and the world becoming a single common market place, quality has gained paramount importance in the process of growth. This is true across the businesses from manufacturing to services. Every business process and operation do involve transformation which is done through adding values into their goods and services which is met as per the wants of the customer. Business leaders are adopting different strategies to overcome the challenges of overgrowing competition. They are using different models, tools and technologies to sense the business environment well in advance. In the recent past, predictive analytics, artificial intelligence, performance measurement and benchmarking have seen extensive applications in business to get competitive advantage. Of these, performance evaluation and benchmarking tools help immensely to identify the best practices, improve performance and to increase the productivity. 
India is one of the largest manufacturers of cement, which is ranked second globally. The cement industry of India is a major contributor to its economy and generates huge employment opportunities. After it was deregulated in 1982, the Indian cement industry has attracted massive investments, both from Indian and overseas investors. Because of the recent boost in infrastructure by the central government, it is anticipated that the cement sector will largely benefit from it. A considerable aspect, which aids the growth of this sector is the availability of raw materials for the production of cement, which also includes limestone and coal. Cement prices in India, grow monthly on an average of $6.7 \%$, thereby indicating the potential growth in extent and profitability of cement in India.

The cement industry in India has a total capacity of about 435 million tones (MT) and the expected growth of cement industry is between 6-7 per cent in 2018, due to the focus on Infrastructural development. Currently, the Cement Industry is producing about $280 \mathrm{MT}$ for its domestic demand and exporting just five MT to the outside world. Owing to the steady demand and descent profit margins, a huge number of foreign players are expected to enter Indian cement sector in the coming future. With the promotion of ease of doing business from the Indian government, lower taxation, and increased infrastructure spending, the sector is expected to grow and take India's economy on a growth trajectory. In the present study, the Cement Industry operating in India has been evaluated using Data Envelopment Analysis (DEA) and Super Efficiency Data Envelopment Analysis (Super Efficiency DEA) for measuring its operational efficiency, productivity and profitability.

\section{Literature Review}

DEA approach has gained a great popularity in the field of Operations Research in the recent past. It's a non-parametric tool based on linear programing, which can be best defined as the ratio of output to input. It can handle multiple inputs and multiple outputs, which can be either financial or non-financial in nature. It has been applied in various fields of business right from education to healthcare, from hospitality to infrastructure, manufacturing, banking, energy, etc. There are elite researchers who have applied DEA in a variety of fields such as education, banking, power, hospitality, healthcare and manufacturing, etc. This section reviews some of the important applications of DEA and other Multi-criteria Decision Making (MCDM) tools for the purpose of performance evaluation and benchmarking in cement industry. Several studies have been undertaken in the past by researchers to measure various forms of efficiency of cement companies. For example, no. of studies have been performed to measure different types of efficiencies such as scale, technical efficiency, financial efficiency as well as energy efficiency.

Scale and technical efficiencies of Iranian cement companies were measured using various techniques such as DEA,TOPSIS, etc. in different studies [10, 13,14]. Similar kind of exercise was undertaken in India [12]. According to the study, foreign firms were found to be technically more efficient than the domestic firms were. In addition, due to the benefits of economies of scale, large-scale firms were found to be more scale efficient than the small- and medium scale firms. Total factor productivit and eco-efficiency amongst Chinese cement manufactures were measured using distance function, and directional slack- based measure (DSBM) for a period from 2005 to 2010 [11]. The results showed that strengthening of environmental regulations is extremely important for China to reduce high-pollution traditional cement kilns. 
Variety of studies were conducted in the past to measure different types of efficiencies such as financial, energy, technical, etc. of the cement industry $[9,10,15]$.

Some studies $[7,8,12]$ focused on measuring environmental efficiency of cement companies. These studies evaluated the ability of a country to simultaneously expand the desirable output and contract the $\mathrm{CO} 2$ emissions by the same proportion without increasing the inputs. The countries where the cement industry invests in technologically advanced kilns and adopt alternative fuels and raw materials in their production processes were found to be eco-efficient.

Thus, from the review of literature we see that most of the studies have focused on application of DEA and other MCDM tools to measure the technical, scale, financial and energy efficiency of cement companies operating in various parts of the world. To the best of our knowledge, no study has taken place using Super efficiency DEA model to measure the performance of a cement company. The Super efficiency DEA model possesses a good discrimination power over DEA while ranking efficient DMUs. Production of cement is highly energy intensive and has severe impact on environment. Therefore, while measuring the operational efficiency, it is extremely critical to consider the amount of energy used in the production of cement. Without this consideration, the estimation process will be inaccurate and incomplete. Few studies $[5,6,8,9]$ were done in this regard a long time ago. Therefore, there is a good scope for studying the latest performance of Indian cement companies using super efficiency DEA model where we use energy expenses as one of the inputs.

The purpose of this study is to evaluate performance of Indian cement companies in terms of effectiveness of their operation's strategies and also to measure their technical and scale efficiencies using DEA and Super efficiency DEA models. Based on the analysis, authors identified the best and the laggard companies, and recommended some of the improvements for the companies having poor performance. These suggestions have managerial implications, which will be of great use to the Decision Maker (DM) in taking corrective actions.

\section{Methodology}

DEA is a non-parametric benchmarking tool, based on linear programming technique originally developed by Farrell [1] and further extended by Charnes, Cooper, and Rhodes [2]. The most commonly used DEA model is the one developed by Charnes, Cooper, and Rhodes (CCR, 1978). Banker, Charnes, and Cooper (BCC, 1984) later reworked upon this model[3]. CCR model measures the relative efficiency of a set of firms that uses a variety of inputs to produce a range of outputs under the assumption of a constant return to scale (CRS) while the BCC model assumes a variable return to scale (VRS). An individual unit in this set (of firms) is referred to as Decision Making Unit (DMU). A DMU, for instance, can include hospitals, power plants, manufacturing units, universities, schools, banks, bank branches, etc. The performance of a DMU is measured using the concept of efficiency or productivity, which is defined as the ratio of total weighted outputs to total weighted inputs.

The DEA method has two approaches namely; input-oriented and output-oriented. In an input-oriented model, desired output is produced by reducing the given set of inputs as much as possible while in an output-oriented model; the output is maximized keeping the input levels fixed. In this study, we have applied output-oriented CRS- DEA (i.e. CCR) and 
output-oriented VRS-DEA (i. e. BCC) models to estimate technical efficiencies of DMUs under study. DEA assigns a score of one to the best performing unit in the set and rest are assigned a score less than one. It forms a piece-wise efficiency frontier, which passes through the best performing units enveloping the remaining less efficient units in the set.

\subsection{Output Oriented CRS-DEA Model}

Let there be N DMUs each with k inputs and m outputs. For the pth DMU under evaluation, the technical efficiency is measured using the CRS-DEA model given in equation (1).

Maximize

Subject to

$$
E_{P}=z=\sum_{I=1}^{K} u_{i p} x_{i p}
$$

$$
\begin{aligned}
& \sum_{j=1}^{m}\left(v_{j p} * y_{j p}\right)=1 \\
& \left.\sum_{j=1}^{M}\left(v_{j p} * y_{j n}\right)-\sum \begin{array}{c}
K \\
\left(\begin{array}{l}
u_{i p} \\
i=1
\end{array}\right.
\end{array} x_{i n}\right) \leq 0 ; n=1,2 \ldots N \\
& \text { With } v_{j m}, u_{i m} \geq \varepsilon ; i=1, \ldots, \mathrm{K}, j=1, \ldots, M
\end{aligned}
$$

where,

$E_{p}:$ Efficiency of the $p^{\text {th }} \mathrm{DMU}$

$x_{i p}$ : value for input criteria $i$ for $p^{\text {th }} \mathrm{DMU}$

$u_{i p}$ : weight of input $i$

$y_{j p}$ : value for output criteria $j$ for $p^{\text {th }} \mathrm{DMU}$

$v_{j p}$ : weight of output $j$

$x_{i n}$ : value for input criteria $i$ for $n^{\text {th }} \mathrm{DMU}$

$y$ : value for output criteria $j$ for $n^{\text {th }} \mathrm{DMU}$

$\varepsilon:$ an infinitesimal or non-Archimedean constant usually in the order

The VRS-DEA model is defined by simply incorporating following convexity constraint to the above CRS-DEA model shown in equation (2).

$$
\sum_{j=1}^{n} \lambda_{n}=1 .
$$

One of the shortcomings of the DEA model is its inability to discriminate between efficient units. In the literature, various modifications/extensions of DEA model have been suggested. One of the most commonly used extension is Super Efficiency DEA model developed by Andersen and Petersen (1993) as described below.

\subsection{Super Efficiency DEA Model}

Super Efficiency DEA is an extension of DEA model. In this study, we use the model developed by Andersen and Petersen [4], which takes a CRS form. This avoids the possibility of non-solution, which may result due to convexity constrained associated with the VRS-BCC model of super efficiency. The output-oriented CRS 
model is described below in equation (3).

Maximize

Subject to

$$
\sum_{k=1}^{s} v_{k} y_{k p}
$$

$$
\begin{aligned}
& \sum_{j=1}^{m} u_{j} x_{j p}=1 \\
& \sum_{k=1}^{s} v_{k} y_{k i}-\sum_{j=1}^{m} u_{j} x_{j i} \leq 0 \forall i \neq p \\
& \sum_{j=1}^{m} \lambda_{j}=1, \quad v_{k} u_{j} \geq 0 \forall k, j
\end{aligned}
$$

Technical Efficiency (TE): The firm's ability to get maximum output from a set of given inputs. Allocative Efficiency (AE): The firm ability to utilize the inputs in an optimal proportion given their respective prices.

Scale Efficiency (SE) of each DMU or Company is given below in equation (4).

$$
\text { Scale Efficiency }=\frac{\text { CRS TE }}{\text { VRS TE }}
$$

In this research, we have used output-oriented CRS-DEA, VRS-DEA models and CRS form of Super Efficiency DEA model to carry out the analysis. The analysis is carried out in two stages. In the first stage, technical and scale efficiencies of all DMUs (cement companies under study) have been calculated using output-oriented CRS-DEA and VRS-DEA models. This analysis assigns an efficiency score to each DMU and identifies efficient and nonefficient DMUs amongst them. As stated earlier, one of the shortcomings of DEA is its poor discrimination power while ranking DMUs. Hence, in the second stage, Super efficiency DEA model is applied to these DMUs not only to measure their performance in terms of efficiency but also to assign them distinct ranks.

\section{Analysis \& Findings}

We have collected data on 17 Indian Cement companies having more than $90 \%$ market capitalization. Data on 4 inputs namely; Raw Material Cost, Power and Fuel Expenses, Salary \& Wages, Total Assets and one output includes Revenue. Inputs such as Raw Material include Limestone, Gypsum and Slag fly ash cost. Power \& Fuel Expenses includes Coal, Petroleum coke and Power plant cost. Employee Cost includes Salary \& Wages, contribution to provident and other funds, and provision for gratuity and staff benefits schemes. The Table 1 shows the input \& output data of Indian Cement companies from the financial year 2017-18. 
Table 1. Input \& Output data on Indian Cement Companies (Figures in Crores)

\begin{tabular}{|c|c|c|c|c|c|c|c|}
\hline DMU & $\begin{array}{c}\text { Company } \\
\text { Name }\end{array}$ & $\begin{array}{c}\text { RawMateri } \\
\text { al Cost }\end{array}$ & $\begin{array}{r}\text { i Power\& } \\
\text { Fuel Cost }\end{array}$ & $\begin{array}{c}\text { Employe } \\
\text { e Cost }\end{array}$ & $\begin{array}{c}\text { Total } \\
\text { Assets }\end{array}$ & $\begin{array}{c}\text { Total } \\
\text { Revenue }\end{array}$ & $\begin{array}{c}\text { Power\&Fu } \\
\text { el Cost as } \\
\% \text { to } \\
\text { Revenue }\end{array}$ \\
\hline \multirow[t]{2}{*}{1} & UltraTech & 3978.36 & 5959.50 & 1706.24 & & 31278.63 & 0.19 \\
\hline & & & & & 54373.0 & & \\
\hline 2 & ACC Ltd & 1982.52 & 2714.45 & 818.95 & 14888.85 & 13262.59 & 0.20 \\
\hline 3 & Shree Cement & 769.06 & 1979.65 & 588.05 & 15141.67 & 10548.58 & 0.19 \\
\hline 4 & Ambuja & 909.33 & 2234.2 & 661.37 & 24617.19 & 11573.96 & 0.19 \\
\hline 5 & Century & 2310.26 & 1571.14 & 657.96 & 10543.68 & 8385.01 & 0.19 \\
\hline 6 & India Cement & 901.38 & 1238.88 & 397.10 & 10977.51 & 5432.54 & 0.23 \\
\hline 7 & Prism & 1305.16 & 732.69 & 413.99 & 5166.84 & 5457.25 & 0.13 \\
\hline 8 & Ramco & 736.68 & 729.07 & 304.85 & 7158.02 & 4616.43 & 0.16 \\
\hline 9 & JK Cement & 730.38 & 889.68 & 325.45 & 5981.98 & 4885.82 & 0.18 \\
\hline 10 & Birla Corp & 633.65 & 1313.14 & 264.51 & 7665.42 & 3944.31 & 0.33 \\
\hline 11 & JK Lakshmi & 662.55 & 917.34 & 262.51 & 5101.08 & 3748.36 & 0.24 \\
\hline 12 & OCL India & 740.20 & 373.52 & 196.40 & 5362.03 & 3564.10 & 0.10 \\
\hline \multirow[t]{2}{*}{13} & Orient & 272.52 & 580.71 & 141.75 & 2940.9 & 2223.40 & 0.26 \\
\hline & & & & & 0 & & \\
\hline 14 & Heidelberg & 356.64 & 443.90 & 120.15 & 2532.82 & 1860.67 & 0.24 \\
\hline 15 & Mangalam & 198.88 & 299.40 & 88.08 & 1219.72 & 1149.48 & 0.26 \\
\hline 16 & KCP Ltd. & 169.13 & 269.40 & 93.45 & 1807.41 & 1023.40 & 0.26 \\
\hline 17 & Sagar Cement & 107.13 & 226.87 & 44.94 & 1216.94 & 747.99 & 0.30 \\
\hline
\end{tabular}

In addition Table 1 also mentions the Power and Fuel cost as percentage to Total Revenue for each company. This figure lies between $10 \%$ (OCL India Ltd.) to $33 \%$ (Birla Corporation) showing wide range. Even the Total Revenue as seen from Table 2 ranges from minimum of Rs.748 Crores (Sagar Cement) to Rs.31279 Crores (UltraTech Cement). Table 2 shows the Descriptive summary of these variables.

Table 2. Descriptive Statistics of Input and Output Variables

\begin{tabular}{ccccccc}
\hline Variable & Mean & SE Mean & Std. Dev. & Minimum & Median & Maximum \\
\hline Raw Material & 986 & 237 & 976 & 107 & 737 & 3978 \\
Power \& Fuel & 1322 & 340 & 1401 & 227 & 890 & 5960
\end{tabular}




\begin{tabular}{ccccccc} 
Employee Cost & 416.8 & 97.8 & 403.4 & 44.9 & 304.9 & 1706.2 \\
Total Assets & 10394 & 3125 & 12887 & 1217 & 5982 & 54373 \\
Total Revenue & 6688 & 1786 & 7363 & 748 & 4616 & 31279 \\
\hline
\end{tabular}

In the first stage of the analysis, we applied output-oriented CRS-DEA and VRS-DEA models to compute TE and SE of these DMUs. Table 3 shows these scores along with individual ranks

Table 3. Technical Efficiencies, Scale Efficiencies and Ranks of DMU

\begin{tabular}{|c|c|c|c|c|c|c|c|}
\hline $\begin{array}{c}\mathbf{D M} \\
\mathbf{U}\end{array}$ & $\begin{array}{l}\text { Company } \\
\text { Name }\end{array}$ & $\begin{array}{c}\text { CRS- } \\
\text { DEA } \\
\text { Efficienc } \\
y\end{array}$ & Rank & $\begin{array}{c}\text { VRS- } \\
\text { DEA } \\
\text { Efficienc } \\
y\end{array}$ & Rank & $\begin{array}{c}\text { Scale } \\
\text { Efficiency }\end{array}$ & Rank \\
\hline 1 & UltraTech & 1 & 1 & 1 & 1 & 1 & 1 \\
\hline 2 & ACC Ltd & 1 & 1 & 1 & 1 & 1 & 1 \\
\hline \multirow[t]{2}{*}{3} & Shree & 1 & 1 & 1 & 1 & 1 & 1 \\
\hline & Cement & & & & & & \\
\hline 4 & Ambuja & 0.9742 & 8 & 1 & 1 & 0.974 & 12 \\
\hline 5 & Century & 0.8609 & 14 & 0.9275 & 12 & 0.928 & 15 \\
\hline 6 & India Cement & 0.7562 & 16 & 0.7564 & 17 & 0.994 & 8 \\
\hline 7 & Prism & 1 & 1 & 1 & 1 & 1 & 1 \\
\hline 8 & Ramco & 0.9224 & 10 & 0.9265 & 13 & 0.996 & 7 \\
\hline 9 & JK Cement & 0.9748 & 7 & 0.9814 & 10 & 0.993 & 9 \\
\hline 10 & Birla Corp & 0.8205 & 15 & 0.8264 & 16 & 0.989 & 10 \\
\hline 11 & JK Lakshmi & 0.8663 & 13 & 0.8766 & 15 & 0.988 & 11 \\
\hline 12 & OCL India & 1 & 1 & 1 & 1 & 1 & 1 \\
\hline 13 & Orient & 0.9506 & 9 & 0.9861 & 9 & 0.953 & 13 \\
\hline 14 & Heidelberg & 0.9184 & 12 & 0.9548 & 11 & 0.938 & 14 \\
\hline 15 & Mangalam & 1 & 1 & 1 & 1 & 1 & 1 \\
\hline 16 & KCP Ltd. & 0.7177 & 17 & 0.8942 & 14 & 0.838 & 16 \\
\hline 17 & Sagar & 0.9213 & 11 & 1 & 1 & 0.782 & 17 \\
\hline & Cement & & & & & & \\
\hline
\end{tabular}

As can be seen from Table 3, that 6 out of 17 companies namely; UltraTech, ACC Ltd, Shree Cement, Prism Cement, OCL India and Managalam Cement emerge as efficient DMUs with overall average technical efficiency score of 0.923 and minimum score of 0.7177 (KCP Ltd). Using VRS-DEA model, eight companies emerge as efficient DMUs with Ambuja Cement 
and Sagar Cement adding to the earlier list obtained by CRS-DEA model.

This is expected due to augmentation of the following convexity constraint shown in equation (5) below

$$
\sum_{j=1}^{m} \lambda_{n}=1
$$

This extra constraint makes it possible to have return-to-scale evaluations allowing more units to become efficient. The overall average efficiency score using VRS-DEA model came out to be 0.949 with minimum score of 0.7564 for India Cement. Further, we obtained scale efficiencies for these DMUs. As observed, companies which were technically efficient using CRS-DEA model, emerge out to be scale efficient as well. The interesting fact to notice from Table 3 is that more than one DMU emerge as technically efficient.

Therefore, in the second stage of our analysis, we have used Super-Radial DEA (Super efficiency DEA) model in the CRS form to further discriminate the performance of efficient DMUs obtained in the first stage. The results from both output-oriented CRS-DEA model and output-oriented Super-radial CRS-DEA model are shown in Table 4 for comparison purpose.

Table 4. Technical and Super Radial efficiencies along with Ranks

\begin{tabular}{rlrrcr}
\hline Sr. No. & Company Name & $\begin{array}{l}\text { (CRS)CCR-DEA } \\
\text { Efficiency }\end{array}$ & Rank & $\begin{array}{l}\text { Super Radial - CCR- } \\
\text { Output Efficiency }\end{array}$ & Rank \\
\hline 1 & UltraTech & 1.0000 & 1 & 1.0170 & 5 \\
2 & ACC Ltd & 1.0000 & 1 & 1.0637 & 4 \\
3 & Shree Cement & 1.0000 & 1 & 1.2872 & 3 \\
4 & Ambuja & 0.9742 & 8 & 0.9742 & 8 \\
5 & Century & 0.8609 & 14 & 0.8609 & 14 \\
6 & India Cement & 0.7562 & 16 & 0.7562 & 16 \\
7 & Prism & 1.0000 & 1 & 1.3048 & 2 \\
8 & Ramco & 0.9224 & 10 & 0.9224 & 10 \\
9 & JK Cement & 0.9748 & 7 & 0.9748 & 7 \\
10 & Birla Corp & 0.8205 & 15 & 0.8205 & 15 \\
11 & JK Lakshmi & 0.8663 & 13 & 0.8663 & 13 \\
12 & OCL India & 1.0000 & 1 & 1.3345 & 9 \\
13 & Orient & 0.9506 & 9 & 0.9506 & 12 \\
14 & Heidelberg & 0.9184 & 12 & 0.9184 & 6 \\
15 & Mangalam & 1.0000 & 1 & 1.0110 & 11 \\
16 & KCP Ltd. & 0.7177 & 17 & 0.7177 & \\
17 & Sagar Cement & 0.9213 & 11 & 0.9213 & \\
\hline
\end{tabular}

Because of the good discrimination power of Super efficiency DEA model, the ranking of DMUs has now become distinct as seen from Table 4. Among the efficient DMUs obtained 
from CRS-DEA model, OCL India Ltd. has emerged as the most efficient DMU while Prism Cement is behind it with second position. It would be interesting to note that big players from Indian Cement Industry such as UltraTech, ACC, Ambuja and Shree cement are not among the leaders even though their revenue and market share are big as compared to other players.

From Table 4, it is evident that there is lot of scope to improve operational efficiency for other DMUs, which came out to be inefficient through this analysis. KCP, JK Cement and India Cement are the companies, which really need to focus on their operational efficiency as they are at the bottom of the list. If we take into account the Power and Fuel cost as percentage to Total Revenue as shown in Table 1, then for the most efficient DMU; OCL India, this percentage is the minimum and for poor performers like KCP Ltd., Birla Corp and India Cement they are between $23 \%$ and $33 \%$ as described above.

\subsection{Critical Analysis of bottom three performers}

Greatest advantage of applying DEA or Super efficiency DEA model for measuring performance is that the individual DMU (firm) in the group gets a detailed performance evaluation report stating areas of improvement as compared to the best performing unit in that group. In addition, the report gives the projection figures for each of the input and output parameters. Below, we discuss the report obtained for the least performing unit in the group namely KCP Ltd.

In this study, we have used output-oriented Supper efficiency model, which tries to increase its output with the given set of inputs. Table 5 gives projection summary and areas for further improvement for KCP in order to improve its performance.

Table 5. KCP Ltd. Efficiency score 0.72 and Rank: 17

\begin{tabular}{llcc}
\hline \multirow{4}{*}{ Inputs } & Projection & Change (\%) \\
& Raw Material & 169.13 & $0.00 \%$ \\
& Power \& Fuel & 269.4 & $0.00 \%$ \\
& Employee Cost & 85.60 & $-8.41 \%$ \\
& Total Assets & 1807.41 & $0.00 \%$ \\
\hline \multirow{2}{*}{ Output } & Revenue & 1425.97 & $39.34 \%$ \\
\hline
\end{tabular}

As seen from the above Table 5, it is advised that KCP Ltd should continue to use the same level of inputs (Raw Material, Power \& Fuel and Total Assets) except for Employee cost, which is expected to come down by $8.41 \%$ from INR. 93.45 Crores to INR 85.60 Crores. It is estimated that with these levels of inputs, company should try to increase its output (Revenue) by $39 \%$. These projections are given after evaluating KCP's performance in comparison with the best performing units in its peer group. 
Table 6 below shows projection summary and areas for further improvement for India Cement Ltd. in order to improve its performance.

Table 6. India Cement Ltd. Efficiency score 0.76 and Rank: 16

\begin{tabular}{llcc}
\hline & & Projection & Change (\%) \\
\hline \multirow{3}{*}{ Inputs } & Raw Material & 901.38 & $0.00 \%$ \\
& Power \& Fuel & 1178.22 & $-4.90 \%$ \\
& Employee Cost & 397.1 & $0.00 \%$ \\
& Total Assets & 10977.51 & $0.00 \%$ \\
\hline Output & Revenue & 7184.38 & $32.25 \%$ \\
\hline
\end{tabular}

As seen from Table 6, India Cement is expected to maintain the same levels of inputs (Raw Material, Employee Cost and Total Asset) except for Power \& Fuel. These charges need to come down marginally from INR 1238.88 cores to INR 1178.22 (by $4.9 \%$ ). With these new levels of input, the company should be able to increase its revenue by $32.25 \%$ going from current level of INR 5432.54 crores to INR 7184.38 crores.

Table 7 below shows projection summary and areas for further improvement for Birla Corporation Ltd. in order to improve its performance.

Table 7. Birla Corporation Ltd. Efficiency Score 0.82 \& Rank: 15

\begin{tabular}{llcc}
\hline \multirow{4}{*}{ Inputs } & Projection & Change (\%) \\
\hline \multirow{7}{*}{ Output } & Raw Material & 633.65 & $0.00 \%$ \\
& Power \& Fuel & 809.71 & $-38.34 \%$ \\
& Employee Cost & 264.51 & $0.00 \%$ \\
& Total Assets & 7665.42 & $0.00 \%$ \\
\hline
\end{tabular}

As seen from Table 7, Birla Corporation is expected to maintain the same levels of inputs (Raw Material, Employee Cost and Total Asset) except for Power \& Fuel. These charges need to come down considerably from current INR 1313.14 Crores to INR 809.71 (by $38.34 \%$ ). With these new levels of input, the company should be able to increase its revenue by $21.87 \%$ going from current level of INR 3944.31 Crores to INR 4807 Crores.

Such projection summary can be obtained for each of the firms under evaluations. These insights can be extremely helpful to the management to increase their effectiveness in terms of their operation's efficiency and thereby increasing total revenue.

\section{Conclusion and Practical Implications}

India is one of the largest manufacturers of cement and is globally ranked at the second 
position. The cement industry of India is a major contributor to its economy and generates huge employment opportunities. After it was deregulated in 1982, the Indian cement industry has attracted massive investments, both from Indian and overseas investors. Because of the recent boost in infrastructure by the central government, it is anticipated that the cement sector will largely benefit from it. A considerable aspect, which aids the growth of this sector, is the availability of raw materials for the production of cement, which also includes limestone and coal. With the promotion of ease of doing business from the Indian government, lower taxation, and increased infrastructure spending, the sector is expected to grow and take India's economy on a growth trajectory.

Cement manufacturing is highly energy sensitive and uses huge amount of energy in terms of coal and electricity to produce cement. This process results in carbon dioxide as an undesirable (by- product) output together with cement as a desirable output. In the era of global warming and depleting energy resources, there is a greater need to evaluate and align cement production process especially in Indian context. The present study is an attempt to evaluate the current status of Indian cement industry in terms of their technical and scale efficiencies. In order to throw some light on energy usage by these companies, power and fuel cost has been considered as one of the inputs with the understanding that more the cost of energy resources, more is the carbon dioxide $\left(\mathrm{CO}_{2}\right)$ emission and more is the production of undesirable output.

The study considers data on 17 major players from Indian cement industry having more that 90 $\%$ market capitalization for the period 2017-18. The results indicate the overall efficiency of this sector at 0.923 , which is a good score, but there is still some scope to improve the total revenue further by $7.7 \%$ with the given set of inputs. In spite of having major market share, and good technical efficiency for companies like UltraTech Cement, ACC Ltd., Ambuja Cement and Shree Cement, the clear winners are OCL India and Prism Cement with super efficiency scores of 1.33 and 1.30 respectively. If we look at their power and fuel expenses as percentage to total revenue, they are at $10 \%$ and $13 \%$ respectively, which is very low as compared to average spending of $19.25 \%$ of four big players mentioned above. It is evident from the study that the big players are not able to take the advantage of economies of scale. They also need to reduce the energy expenses and become energy efficient in order to sustain their position in the markets going forward. With the strict implementation of the environmental regulation, Indian cement companies need to align their production process to reduce the undesirable outputs such as emission of carbon dioxide, sulfur dioxide and production of other pollutants as particulate matter.

\section{Research Limitations and Future Scope}

There are certain limitations of this study. As mentioned above, the cement industry is highly energy sensitive. With depleting energy resources, there is a greater need to focus on reducing the use of these resources in the production of cement. Therefore, going forward a similar study can be taken up using input-oriented DEA models, which can evaluate the performance of these companies in terms of their energy efficiency. Energy efficiency can be defined as the ability of the producerto reduce energy resources and produce maximum amount of cement as a desirable output. 
With environmental regulations coming in full force and compliance to these becoming extremely critical, it would be important to study the environmental efficiency of these companies. Due to unavailability of required data, current study could not consider this aspect of performance measurement.

\section{References}

[1] Farrell, M. J.:'The Measurement of Productive Efficiency', Journal of the Royal Statistical Society, 120(3), pp. 253-290. (1957)

[2] Charnes, A., Cooper, W. W. \& Rhodes, E.: Measuring the efficiency of decision making units. European journal of operational research, 2, pp. 429-444. (1978)

[3] Banker, R.D., Charnes, A. \& Cooper, W. W.: Some models for estimating technical and scale inefficiencies in data envelopment analysis. Management science, 30, pp. 1078-1092. (1984)

[4] Andersen, P., \& Petersen, N. C.: A procedure for ranking efficient units in data envelopment analysis. Management science, 39(10), pp. 1261-1264, (1993)

[5] Kumar Mandal S. \& Madheswaran S.: Environmental efficiency of the Indian cement industry: An interstate analysis. Energy Policy, 38(2), pp. 1108-1118. (2010).

[6] Mandal S. K.: Do undesirable output and environmental reg-ulation matter in energy efficiency analysis? Evidence from Indian cement industry. Energy Policy, 38(10), pp. 6076- 6083. (2010)

[7] Bandyopadhyay S.: In search of contextual variables in a stochastic DEA framework: Effect of regulation on efficiency of Indian cement industry. Journal of the Operational Research Society, 62(9), pp. 1621-1637. (2011)

[8] Oggioni G., Riccardi R., \& Toninelli R.: Eco-efficiency of the world cement industry: A data envelopment analysis. Energy Policy, 39(5), pp. 2842-2854 (2011)

[9] Mandal S. K., Madheswaran S: Productivity Growth in Indian Cement Industry :Panel Estimation of Stochastic Production Frontier. The Journal of Developing Areas, 46(1), pp. 287- 303 (2012)

[10] Mansouri A., Ebrahimi N., \& Ramazani M.: Ranking of Companies based on TOPSIS- DEA Approach Methods. Pakistan Journal of Statistics and Operation Research, 10(2), pp. 189. (2014)

[11] Long X., Zhao X., \& Cheng F.: The comparison analysis of total factor productivity and ecoefficiency in China's cement manufactures. Energy Policy, 81, pp. 61-66. (2015)

[12] Kundi M. \& Sharma S.: Efficiency Analysis and Flexibility: A Case Study of Cement Firms in India. Global Journal of Flexible Systems Management, 16(3), pp. 221-234. (2015)

[13] Abbasi M. \& Kaviani M. A.: Operational efficiency-based ranking framework using uncertain DEA methods: An application to the cement industry in Iran., pp. 902-928 (2016)

[14] Alimohammadkou M \& Mohammadi S.:Evaluating the Productivity Using Malmquist Index Based on Double Frontier Data. Procedia-Social and Behvioral Sciences. Pp58-66 (2016)

[15] Anwar S. \& Afrizalmi L.: An Evaluation of Energy Efficiency in Cement Plants using Data Envelopment Analysis Approach. National IENASCO, pp. 43-49. (2016) 